\title{
As Interações Virtuais entre Clientes e Gerência de Hotéis do Brasil: um estudo sob a ótica da Teoria da Atribuição
}

\author{
Las Interacciones virtuales entre Clientes y Gerencia de Hoteles de Brasil: un estudio bajo la óptica de la Teoría de la \\ Atribución \\ The Virtual Interactions between Customers and Hotel Management in Brazil: a study from the viewpoint of \\ Attribution Theory
}

Camila Prata Macedo

Universidade Estadual do Ceará(UECE), Brasil

camilaprata96@hotmail.com

DOI: https://doi.org/10.18472/cvt.19n3.2019.1552

Redalyc: http://www.redalyc.org/articulo.oa?

$\mathrm{id}=115461709012$

Gizmelry Fontes Portela

Universidade Estadual do Ceará(UECE), Brasil

gizmelryfontes@yahoo.com.br

Ana Augusta Ferreira de Freitas

Universidade Estadual do Ceará(UECE), Brasil

ana.freitas@uece.br

Recepción: 26 Diciembre 2017

Aprobación: 11 Noviembre 2019

\section{Resumo:}

Objetivou-se com esse estudo analisar o comportamento de hotéis no site TripAdvisor.com, a partir das três dimensões da teoria da atribuição: causa, controle e responsabilidade. Em termos de corpus empírico, a pesquisa baseou-se na análise de 300 comentários escolhidos após aplicação de alguns filtros, que foram extraídos dessa plataforma de revisões online, tomando por base 31 hotéis. Os resultados indicaram inicialmente que a maioria das reclamações feitas pelos hóspedes tinham relação com a Infraestrutura, com os Serviços e com o Atendimento. Uma análise do conteúdo dos comentários mostrou que os clientes percebem que a culpa dos acontecimentos ruins é, em sua maioria, do hotel. Mostrou ainda que eles acreditam que os problemas identificados tinham causas estáveis, e que poderiam ter sido controlados pelas empresas, já que em suas visões elas eram responsáveis pelos ocorridos. Implicações de natureza gerencial são indicadas no texto a partir dos achados, visando refletir sobre o desempenho dos hotéis quanto ao relacionamento com os seus clientes, e a possibilidade destes adotarem métodos de abordagem e tratamento das informações disponíveis em plataformas virtuais.

Palavras-chave: Teoria da Atribuição, Mídias Sociais, Setor Hoteleiro.

\section{Abstract:}

The objective of this study was to analyze the behavior of hotels on TripAdvisor.com, from the three dimensions of attribution theory: cause, control and responsibility. In terms of empirical corpus, the research was based on the analysis of 300 comments chosen after applying some filters, which were extracted from this online review platform, based on 31 hotels. The results initially indicated that most complaints made by guests were related to Infrastructure, Services and Customer Service. A review of the content of the reviews showed that customers realize that the blame for the bad events is mostly the hotel. It also showed that they believe that the problems identified had stable causes, and that they could have been controlled by the companies, as in their view they were responsible for what occurred. Implications of a managerial nature are indicated in the text from the findings, aiming to reflect on the hotels performance in relation to their customers, and the possibility of them adopting methods of approach and treatment of information available on virtual platforms.

KEYWORDS: Theory of Attribution, Social media, Hotel sector.

\section{Resumen:}

El objetivo de este estudio fue analizar el comportamiento de los hoteles en TripAdvisor.com, desde las tres dimensiones de la teoría de la atribución: causa, control y responsabilidad. En términos de corpus empírico, la investigación se basó en el análisis de 300 comentarios elegidos después de aplicar algunos filtros, que se extrajeron de esta plataforma de revisión en línea, basada en 31 hoteles. Los resultados inicialmente indicaron que la mayoría de las quejas presentadas por los huéspedes estaban relacionadas con 
Infraestructura, Servicios y Servicio al Cliente. Una revisión del contenido de las revisiones mostró que los clientes se dan cuenta de que la culpa de los malos eventos es principalmente el hotel. También demostró que creen que los problemas identificados tienen causas estables y que podrían haber sido controlados por las empresas, ya que, en su opinión, eran responsables de lo ocurrido. Las implicaciones de carácter gerencial se indican en el texto de los hallazgos, con el objetivo de reflexionar sobre el desempeño de los hoteles en relación con sus clientes, y la posibilidad de que adopten métodos de enfoque y tratamiento de la información disponible en plataformas virtuales.

Palabras clave: Teoría de la asignación, Redes sociales, Sector Hotelero.

\section{INTRODUÇÃO}

Em um mercado cada vez mais competitivo onde quem comanda as relações são os clientes, devido ao seu poder de compra, estes estão se tornando cada vez mais exigentes e informados sobre os produtos ou serviços que adquirem (KOTLER, 2010). Nesse contexto, a internet tem se tornado uma ferramenta de auxílio de troca de informações, expressão de pensamentos, opiniões e avaliação de experiências vividas, que podem influenciar futuros consumidores.

Diante do poder das informações lançadas na Internet, os gestores precisam entender a influência da repercussão de informações nas mídias em suas organizações, tendo em vista que comentários negativos poderão denegrir a imagem da empresa, devido ao alcance que as mídias sociais possuem (DELLAROCAS, 2003).

No setor hoteleiro não é diferente. Com a popularização de sites de viagens como o TripAdvisor.com, onde viajantes podem expressar suas opiniões sobre suas hospedagens e visualizar as avaliações de outros viajantes, os gestores devem ficar atentos a esses comentários, pois as impressões deixadas para o consumidor são cruciais para que ele possa retornar, ou não, a consumir um produto ou serviço de uma empresa. Tal percepção é fundamental para o desenvolvimento deste estudo, pois direciona o conteúdo a ser explorado, e contribui para a escolha do objeto de interesse. Nesse caso, as duas vertentes teóricas no qual esse trabalho se baseia são a teoria da atribuição e as interações entre cliente e empresa nas plataformas virtuais.

A teoria da atribuição está relacionada às emoções que são percebidas pelo indivíduo frente a situações positivas ou negativas que os afetam, gerando uma busca pelos fatores causa, controle e responsabilidade de tais ocorrências, capazes de criar sentimentos de raiva e gratidão (WEINER, 2000; LOPES, 2009). A busca pelo entendimento dos resultados é característica da teoria atributiva, mas apontar um culpado pelo ocorrido é o seu objeto de estudo.

Este trabalho busca responder à seguinte questão de pesquisa: qual a postura de hotéis no TripAdvisor.com, frente a comentários, à luz da Teoria da Atribuição? O objetivo principal consiste em analisar a postura de hotéis no TripAdvisor.com, de acordo com as três dimensões da teoria da atribuição: causa, controle e responsabilidade.

\section{REFERENCIAL TEÓRICO}

Inicialmente, apresenta-se o contexto da teoria da atribuição, onde o conceito é definido e as três dimensões da teoria são explanadas, fazendo uma relação com o comportamento de consumo pós-compra de um indivíduo. Em seguida, será abordado o uso das mídias, com o intuito de apresentar as interações que a Internet pode proporcionar em relação a comentários feitos por consumidores. 


\subsection{Teoria da Atribuição}

Segundo Lopes (2009), a teoria da atribuição está diretamente ligada às emoções dos indivíduos, que analisam as causas de acontecimentos que os afetam, e que gera um julgamento sobre tais ocorridos. $\mathrm{Na}$ seara do comportamento do consumidor, esta avaliação feita reflete-se no comportamento de consumo, no que diz respeito a sua propensão em retornar a um provedor de serviço ou recompra de um produto. A teoria indica que as atribuições causais, derivadas do julgamento das situações positivas ou negativas, podem causar sentimentos como gratidão ou raiva (WEINER, 2000). Isto significa que, ao comprar um produto ou pagar por um serviço, o consumidor está sujeito a passar por experiências e a partir dessa situação ele pode concluir se o acontecido foi bom ou ruim, através das dimensões da atribuição (WEINER, 2000).

Para Weiner (2000), a pesquisa atributiva está mais relacionada ao estudo das falhas, ou dissatisfaction, como ele refere-se, do que com o sucesso, à medida que se percebe que o indivíduo está mais preocupado em buscar o responsável por produto/serviço que não funciona, do que um que não apresenta defeitos.

Lopes, Freitas e Mota (2015) afirmam que quando se encontra uma causa para um acontecimento de falha, sentimentos são desenvolvidos e por meio destes se consegue obter previsões (ou pistas) acerca do comportamento futuro de consumo dos indivíduos. Porém, estes mesmos autores acreditam que tal percepção em relação ao sentimento pós compra dos indivíduos possuem baixa visibilidade pelos estudiosos. A fim de utilizá-los como medidas de análise comportamental em si, em seu estudo trazem a relação entre a teoria da atribuição e a ruptura de clientes, pois essa é desencadeada, na maioria das vezes, por "percepções negativas, sentimentos desconfortáveis e reclamações” (LOPES; FREITAS; MOTA, 2015, p. 39).

Da derivação de vários estudos, inclusive os de Weiner (2000), surgiram as dimensões atribucionais que hoje são utilizadas para pesquisas e análises em diversas situações como o comportamento do consumidor após a etapa de compra de um produto ou serviço, com o intuito de obter previsões futuras. As dimensões atribucionais são causa, controle e responsabilidade. Tais variáveis são meios pelo qual se identifica o porquê da ocorrência de um evento, principalmente, se esse tiver como resultado uma falha.

Ao identificar um erro em um produto ou serviço, o consumidor busca entender o motivo de sua ocorrência, ou seja, a causa do seu acontecimento. Weiner (2000) traz uma característica da primeira dimensão, a causa, chamada de estabilidade, a qual faz referência à continuidade ou à raridade do problema apresentado, além de envolver a reação do indivíduo perante tal resultado. As atribuições causais, com relação à estabilidade, podem ser estáveis ou instáveis. Como por exemplo, em um aeroporto, quando o atraso de um voo ocorre devido às condições climáticas não estarem favoráveis, é uma causa instável. Por outro lado, quando esse atraso ocorre devido a uma greve dos controladores de voo é uma causa estável (FOLKES; KOLETSKY; GRAHAM, 1987).

Segundo Folkes, Koletsky e Graham (1987), quando ocorrem falhas no produto ou serviço devido a causas estáveis, podem ser diminuídas as futuras intenções de compra dos clientes, pois estes já esperam futuros problemas ao contratar a empresa novamente. Caso o erro decorra de uma causa percebida como instável, os consumidores possuem menor certeza de erros no futuro e, dessa forma, estão mais propensos a contratarem essa empresa outra vez. Para Tomlinson e Mayer (2009), a causa indica o que esperar no futuro em situações similares. Folkes, Koletsky e Graham (1987) e Weiner (2000) corroboram que as atribuições feitas pelas causas de algo que tenha acontecido influenciam o desejo de recompra do consumidor e podem ocasionar a sua rejeição pela empresa.

Segundo Tomlinson e Mayer (2009), o controle, segunda dimensão, diz respeito ao grau de controle inicial de um indivíduo sobre o resultado, ou seja, o controle que ele tinha para evitar que algo acontecesse. Folkes, Koletsky e Graham (1987) explicam que o controle da situação pode influenciar na recompra, pois caso o cliente perceba que a situação poderia ter sido evitada pelos funcionários de uma organização ou por um prestador de serviço, o cliente portar-se-á de maneira negativa. Prado e Farias (1998, p.4) afirmam também que "problemas atribuídos a fontes externas (controláveis pelos profissionais de marketing) têm 
probabilidade maior de gerar uma resposta insatisfatória do que problemas atribuídos a fontes internas". Nesse caso, os autores usam o termo fontes internas para problemas onde o cliente está no controle da situação e fontes externas quando os funcionários da empresa é que estão.

Junto com o controle são desenvolvidos sentimentos como raiva e ira, por exemplo, que podem influenciar indiretamente na recompra com a empresa. Quando o cliente percebe que a empresa tinha a capacidade de controlar a situação e não o fez, surge a raiva e com ela, pode-se manifestar a negação contra a empresa, e a intenção de recompra com a empresa pode acabar (FOLKES; KOLETSKY; GRAHAM ,1987).

Em se tratando da terceira dimensão da teoria da atribuição, a responsabilidade, Folkes (1988) traz a ideia de locus que está associado a quem deve resolver os problemas. O termo locus vem do latim que significa lugar. Dessa forma, o locus da causa ou lugar de origem da causa indica de onde ela surgiu, ou seja, quem é o responsável pela causa da situação, que de acordo com Lopes (2009) pode ser o consumidor ou a empresa. Quando a empresa é a responsável pela falha, esta deve reparar a falha e pedir desculpas aos seus clientes. Porém, quando o erro é dos consumidores, eles são responsáveis pelo ocorrido e as empresas não são obrigadas a fornecer reparação (FOLKES, 1988).

Segundo Weiner (2000) as pesquisas com o intuito de estudar e analisar os comportamentos dos consumidores passaram a surgir, observando os fatores determinantes desses comportamentos. Logo, compreende-se que a teoria da atribuição se conectou com o estudo do comportamento do consumidor a fim de explicar como o pensamento e a emoção em conjunto influenciam a maneira como os consumidores se portam frente às situações positivas e negativas do cotidiano do consumo.

Em situações de consumo, as emoções surgem quando os consumidores avaliam as ocorrências ou situações vividas com a compra de um produto ou contratação de um serviço, de forma psicológica. Cada indivíduo avalia de forma individual e diferente uma situação (MEDEIROS; GOSLING; VERA, 2015). Ao passar por determinadas situações, os clientes analisam e julgam se o resultado entregue foi o esperado, caso não tenha sido, buscam respostas da empresa, e a partir daí, manifestam suas emoções.

Tais emoções produzem nos consumidores o sentimento de satisfação ou insatisfação, que podem gerar a lealdade e indicação dos produtos/serviços ou levar os clientes a reclamarem ou destinarem comentários prejudiciais às empresas (MEDEIROS; GOSLING; VERA, 2015).

Tal situação é potencializada pela Internet, que abriu as portas para o diálogo e para a interação social, com informações estando mais propensas à dispersão, e os consumidores mais ativos nas mídias em busca destas. As mídias passaram a ser canais comunicativos entre empresa e cliente, o que exige conhecimento e agilidade para o manuseio de respostas.

\subsection{Interação Virtual nas Mídias Sociais}

Com o advento da Internet, diversas informações passaram a girar em torno dela, e isso fez com que as mídias sociais se tornassem o centro das atenções, pois, tornou-se o meio mais prático das pessoas divulgarem o que estão sentindo, pensando e o que gostariam de compartilhar. Assim, as mídias sociais passaram a ser bastante visadas pelas empresas, a fim de se aproximarem de seus clientes, como também se tornaram alvos fáceis dos julgamentos desses indivíduos (MACLENNAN et al., 2014).

Conforme Kocak (2015), mídias sociais se definem como o conjunto de três elementos: conteúdo, que se refere às informações criadas pelos usuários, comunidade, grupos que se formam e que adquirem um maior número de conteúdos possíveis e a $W e b 2.0$, plataforma para o desenvolvimento de tecnologias para geração de informações e compartilhamento de opiniões. No geral, entende-se que as mídias são ferramentas promotoras de interações sociais para armazenagem e dispersão de ideias, opinióes, experiências, entre muitos outros, sendo compartilhados em diversos formatos como textos, fotos e vídeos (SOUSA; AZEVEDO, 2010). 
Por ser de tão fácil interatividade e dispersão, as mídias sociais acabam se tornando um dos principais meios de busca sobre informações acerca de qualquer coisa, sejam pessoas, lugares, produtos, serviços, entre outros (MACLENNAN et al., 2014). Já diziam Kotler e Armstrong (2007), que os indivíduos antes de efetuarem uma compra vão em busca de informações sobre a popularidade e credibilidade de um produto ou serviço no mercado, classificando tal fato como uma etapa do processo de decisão de compra. Muitas vezes, a busca se faz por meio de mídias sociais que são voltados para a opinião do consumidor (como TripAdvisor.com, Reclameaqui.com, Booking.com, Facebook, entre outros).

As redes sociais não permitiram apenas que os consumidores compartilhassem ideias, informações, opiniões com outros consumidores, elas também possibilitaram que reclamações fossem feitas acerca de produtos e serviços, que foram sinônimos de insatisfação para esses indivíduos (CLÁUDIO; PEDRON; GONÇALVES, 2014). Para Limberger, Boaria e Anjo, (2014, p. 437), "A mídia social integra o marketing digital e alude a influência interpessoal online ou o boca a boca online."

Segundo Kocak (2015), as práticas de comunicação entre hotéis e seus clientes já eram bem difundidas, quando estes utilizavam cartões de comentários e até os dados dos próprios clientes para gerar interatividade. No entanto, com o advento da $W e b 2.0$ que permite a interatividade imediata de informações, criou-se a necessidade de adaptar-se a um novo cenário da tecnologia. $\mathrm{O}$ autor afirma que, diante dessa nova experiência, percebeu-se o quão importante é para uma empresa, de todos os setores, particularmente da hotelaria, aprimorar as suas técnicas de gerenciamento tanto de suas mídias internas (perfis no Facebook, Twitter, Instagram, sites, por exemplo) como das mídias externas (sites de reclamação, sites voltados para viagens, entre outros).

Muitas empresas acreditam que as reclamações são empecilhos para a organização, e, de fato, o são, se não forem geridas ao ponto de serem solucionadas (CLÁUDIO; PEDRON; GONÇALVES, 2014). A importância da gestão das mídias se dá pelo fato de que a maioria das reclamações são feitas em veículos como sites, blogs, e até pelas redes sociais das próprias empresas. Então, quando há um monitoramento e uma busca pela melhora, rompimentos podem ser evitados e a satisfação pode ser desenvolvida no consumidor (CLÁUDIO; PEDRON; GONÇALVES, 2014; KOCAK, 2015; MACLENNAN et al., 2014). Limberger, Boaria e Dos Anjos (2014) asseveram que as empresas de hotelaria que integraram as mídias sociais com o seu CRM (Customer Relationship Management) são capazes de medir a satisfação dos clientes, resolver queixas, entre outras vantagens.

$\mathrm{O}$ ato de reclamar pode significar que o cliente deseja ser reembolsado ou que lhe possa ser devolvido o que não lhe foi entregue, ou seja, um bom serviço ou um bom produto (CLÁUDIO; PEDRON; GONÇALVES, 2014). Ao apresentar uma resposta justa, a empresa está reconquistando os seus clientes, pois é gerada satisfação com relação ao processo de resposta, o que reflete em possíveis recompras e um boca a boca positivo. Ao contrário de um processo negativo, tardio, ou que não gerou respostas para o consumidor, que pode desenvolver o desligamento do mesmo e ainda gerar um boca a boca negativo.

Como afirmam Maclennan et al. (2014. p. 70) "quanto maior for a intensidade da visualização de informações ou opiniões online, maior a sua influência nas decisões de compra”. Por isso, hoje, faz-se necessário que as empresas possuam controle sobre as reclamações direcionadas a elas, ou seja, que se tenha um bom gerenciamento de reclamações. Para Santos e Rossi (2002) o gerenciamento de reclamações está voltado, principalmente, para os serviços, e é caracterizado pelas interações que são feitas entre empresa e cliente, quando o mesmo registra queixas contra a empresa.

Santos e Rossi (2002) afirmam, também, que as perspectivas dos consumidores frente às atitudes das empresas com relação às reclamações refletem na lealdade e na confiança destes, contribuindo para a confirmação de que quando uma empresa possui um controle sobre as queixas, que a estas são direcionadas, há uma maior probabilidade de estabelecer um vínculo positivo com o seu cliente.

Quando uma compra é realizada, os clientes tendem a criar expectativas a respeito de um produto/serviço. $\mathrm{Na}$ etapa de pós-compra os indivíduos passam a avaliar tais expectativas com o verdadeiro resultado oferecido 
(CLÁUDIO; PEDRON; GONÇALVES, 2014). Diante disso, sentimentos são desenvolvidos quando um resultado é esperado, superior ao esperado e inferior ao esperado, transmitindo, neutralidade, satisfação e insatisfação, respectivamente (CLÁUDIO; PEDRON; GONÇALVES, 2014; WEINER, 2000).

Em todo o mundo, diversas pessoas utilizam as mídias sociais como um meio de busca para obter informações sobre destinos desejados. Da mesma forma que buscam referências sobre estes locais, elas também alimentam esses sites com suas opiniões após realizarem suas viagens. Essas informações procuradas, geralmente são de outras pessoas que viajaram para o local e que narram suas experiências em blogs, microblogs, comunidades online ou sites (LEUNG; LAW; HOOF; BUHALIS, 2013).

Tendo em vista essa grande repercussão de informações nas mídias, devido à liberdade de comentários nas redes, os gestores das organizações precisam perceber o impacto que isso promove em suas organizações, atingindo um grande grupo de atividades (DELLAROCAS, 2003), pois quando um viajante coloca sua opinião em relação a sua hospedagem em uma comunidade online, por exemplo, todos terão acesso a seu comentário, e se caso for ruim, poderá prejudicar o nome da empresa. Porém isso pode ser revertido, caso o hotel de posicione sobre a situação através de uma resposta.

Hoje, sites de viagens, como o TripAdvisor.com, viraram sites-alvo dos consumidores, em relação a sua popularidade e credibilidade quando se trata de classificação e informações acerca de hotéis. Contudo, as empresas, muitas vezes, não conseguem visualizar a importância desses sites para o seu desenvolvimento, visto que esses permitem que as empresas hoteleiras tenham um controle de suas forças e fraquezas, consigam medir o grau de satisfação do cliente, além de poder aumentar a visibilidade do negócio no mercado (LIMBERGER; BOARIA; ANJOS; 2014).

\section{METODOLOGIA}

Este trabalho foi desenvolvido com base em uma análise do site de busca de viagens, TripAdvisor.com com o propósito de identificar, por meio dos comentários e respostas expostos nestes ambientes, o comportamento dos consumidores no setor hoteleiro. A finalidade será confrontar as informações colhidas com a teoria da atribuição, apresentadas na literatura, e verificar qual a postura dos gestores dessas empresas de acordo com suas respostas às postagens feitas pelos consumidores.

Esta pesquisa busca fazer uma análise das interações virtuais entre comentários dos viajantes e respostas dos hotéis. A coleta de dados foi realizada através da extração de comentários de viajantes e respostas de empresas hoteleiras no site TripAdvisor.com. Foi escolhido um período de mais de um ano porque se entendeu que seria importante para contemplar eventuais alterações ao longo do ano.

Os critérios para escolha das unidades de análise foram comentários em português (Brasil) que obtiveram respostas de hotéis. As empresas deveriam pertencer a redes hoteleiras, totalizando 31 hotéis explorados em 13 redes. Além disso, determinou-se um número mínimo de 1000 avaliações no site Tripadivisor.com para cada empresa pela maior confiabilidade gerada através da frequência de usuários inserindo comentários. Com base nesses critérios foram selecionadas 300 interações por serem completas, ou seja, por existirem respostas de ambas as partes interessadas.

Foi realizada uma análise de conteúdo das interações, que é uma técnica metodológica que visa obter, por procedimentos sistemáticos e objetivos de descrição do conteúdo das mensagens, indicadores que permitem a inferência de conhecimentos relativos às condições de produção destas mensagens (BARDIN, 2011). Tal análise foi feita de forma manual, sem apoio de um software específico.

A partir da análise de conteúdo, foram observados nos comentários dos viajantes seus principais objetos de reclamação, as dimensões da teoria da atribuição em sua visão, seus sentimentos percebidos, o destaque dado por eles em seus comentários e as solicitações feitas. Já nas respostas dos hotéis observaram-se as suas posturas em relação à causa, ao controle e a responsabilidade do problema apresentado, os mecanismos de recuperação usados por eles, além de observar se a resposta da empresa era programada (utiliza a mesma resposta para vários 
comentários) ou interativa (resposta individual para cada comentário) e se a empresa respondeu a todos as observações levantadas pelos clientes.

Dentre as categorias, as que tratam da causa, controle e responsabilidade são originadas do referencial teórico (WEINER, 2000). As demais categorias emergiram durante a análise dos dados, feita por meio da técnica de análise de conteúdo. Diante dessa análise, foram desenvolvidas treze categorias de avaliação mostradas no Quadro 1 abaixo que especifica o que foram analisadas em cada uma delas:

Quadro 1 - Categorias analisadas nos comentários gerados entre Hóspede e Hotel

\begin{tabular}{|c|c|}
\hline CATEGORIAS & ESPECIFICAČÃO \\
\hline Gênero & Observação do sexo dos hóspedes dos comentários \\
\hline Objetos da Reclamação 1,2 e 3 & Observação do que o hóspede considera como problema no hotel \\
\hline Causa (visão do cliente) & Observação da natureza da causa na visão do hóspede (instável ou estável) \\
\hline Controle (visão do cliente) & Observação acerca da atribuição de quem possui o controle do problema na visão do hóspede \\
\hline Responsabilidade (visão do cliente) & Observação acerca da atribuição de quem possui a responsabilidade do problema na visẫo do hóspede \\
\hline Sentimentos 1 e 2 & Observação dos sentimentos identificados na fala do hóspede \\
\hline Destaques & Observação das formas de realce em comentários ou sentimentos (caixa alta e emojis) \\
\hline Solicitaçã̃o & Identificaçăo de solicitações feitas pelo hóspede à empresa \\
\hline Postura da Empresa (com relação à causa) & Explicação da empresa sobre a instabilidade da causa \\
\hline Postura da Empresa (com relação ao controle) & Explicaçấo da empresa sobre o controle da causa \\
\hline Postura da Empresa (com relação a responsabilidade) & Explicação da empresa sobre a responsabilidade da causa \\
\hline Postura da Empresa (mecanismos de recuperação 1 e 2) & Resposta que a empresa dá ao comentário em relação ao problema, e oferta de benefício ao hóspede \\
\hline Formato da Resposta & Tipo de resposta que a empresa dá (interativa ou programada) \\
\hline Apresentação de Pedido de Desculpas & Identificação de pedido de desculpas da empresa para o hóspede \\
\hline Apresentação de Resposta (quanto ao comentário) & Observação acerca da resposta (se atendeu ou não a todas as reclamações citadas pelos hóspedes) \\
\hline
\end{tabular}

Fonte: Elaborado pelos autores (2017)

No quadro acima, a categoria 'objetos da reclamação' teve como subcategorias despontadas: infraestrutura, limpeza, serviço e atendimento. Infraestrutura: estado de conservação do hotel, estrutura antiga, estrutura sem funcionalidade, equipamentos sem funcionar, falta de equipamentos ou móveis, entre outros. Limpeza: falta de limpeza ou limpeza precária nas dependências usadas no hotel. Serviço: a prestação de serviços de quarto, problemas ou falta de internet, problemas com o serviço no restaurante, itens não consumidos inclusos na conta do hotel, entre outros. Atendimento: falta de assistência, suporte, acolhimento, presteza, cortesia no atendimento aos hóspedes. Bem-estar: Situações vivenciadas no hotel provocaram um mal-estar ou doença. Localização: Referente a lugar onde o hotel está situado. Todas essas categorias e subcategorias são propostas para formar nova teoria a partir de análise dos dados.

\section{ANÁLISE DOS RESULTADOS}

Os comentários foram feitos por pessoas que se hospedaram no hotel (hóspedes) e, na maioria dos casos, as respostas são dos gerentes de hotéis. As interações virtuais entre hóspede e gerentes foram o objeto de estudo deste trabalho e contribuíram para que fossem identificados os dados que serão apresentados a seguir.

Os primeiros resultados demonstraram que, em se tratando dos objetos de reclamação expostos pelos clientes, os mais mencionados como primeira opção, de acordo com as categorias estabelecidas foram, respectivamente: infraestrutura (47\%), serviços (22\%) e atendimento (21\%), seguidos de limpeza ( $8 \%)$, bemestar (1\%) e localização (1\%).

Diante disso, pode-se entender que a maioria dos hóspedes mencionavam como problemas fatores como a estrutura antiga do hotel, defeitos em quartos e banheiros, além de demonstrarem insatisfação quanto a serviços de café-da-manhã e de quarto e criticavam o atendimento da recepção e de outros funcionários. 
Outra parcela apresentou críticas ao serviço de limpeza; e questões de bem-estar ao afirmarem que não se sentiram bem com o ambiente do hotel, ou que ficaram doentes por causa da hospedagem no hotel.

Com relação aos três pilares da Teoria Atributiva, - causa, controle e responsabilidade obteve-se os seguintes resultados: na maioria dos comentários os hóspedes deixaram bem claro que para eles as causas eram estáveis (ou seja, eles entendem que os problemas mencionados permanecerão por um bom tempo ainda no hotel). Para Tomlinson e Mayer (2009), a causa é um fator que indica o que o indivíduo irá esperar no futuro em casos parecidos, ou seja, qual será o comportamento dos interessados diante de uma nova ocorrência. A posição da gerência dos hotéis quanto a esse fator, foi de que as causas eram, na maioria, instáveis, compreendendo assim uma possível tentativa de recuperar o cliente ou de informá-los que os problemas já teriam sido resolvidos. Para melhor explicar o que foi dito acima, tem-se o seguinte exemplo:

unidade ruim Se for para ficar apenas uma noite, vale pelo custo benefício dependendo dá localização que você for estar. Mais de doisagar mais caro [....] Embora o atendimento dos funcionários é para admirar as acomodações estão ruim e com cheiro forte. (Hóspede)

prezado [....] Agradecemos os comentários sobre nossos serviços e estrutura. Sempre é bom este feedback para direcionar e priorizar ações, em especial, sobre os quartos, como o período de chuvas (alta m umidade) está passando, já é hora de nova ação para eliminar os pontos de mofo. Sejas sempre bem vindo [....] (Gerência)

Como se pode observar, de acordo com a gerência o problema mencionado pelo hóspede possui causa instável, ou seja, como a região do hotel está no período de chuvas é compreensível que existam problemas com mofo, e mau cheiro, passando a mensagem de que após o período chuvoso, se tenha controle sobre a situação, e não haverá mais problemas como o citado.

Ao olhar para o fator controle, esse explorado pela Teoria Atributiva, informa-se que segundo Weiner (2000) a parte provedora do produto ou serviço deve exercer domínio sobre as situações, sejam positivas ou negativas, resultantes do funcionamento ou desempenho deles. De acordo com a análise, para os hóspedes a quase totalidade das situações apresentadas por eles poderiam ter sido controladas pelo hotel. Isso mostra que na visão dos hóspedes o hotel tinha capacidade de solucionar os problemas mencionados, mas não o fez o que gerou um desconforto e insatisfação nos hóspedes. Olhando pelo lado da gerência, três quartos dos gerentes de hotéis, afirmaram que tinham controle sobre a situação. Folkes, Koletsky e Graham (1987) afirmam que ao perceber que uma situação poderia ter sido controlada, o cliente diminui suas chances de recompra, desencadeando comentários negativos. Observando o exemplo abaixo:

diária de $\mathrm{R} \$ 800,00$ (carro batido) Eu e meu marido nos hospedamos uma noite neste hotel, e deixamos o nosso carro no estacionamento do mesmo. A hospedagem foi normal [.... O problema foi com o nosso carro. Quando retiramos o carro, o manobrista perguntou se íamos guardar as bagagens no porta mala, eu disse q sim, e ele mesmo abriu, para esconder o que tinha acontecido e deu certo. Só quando chegamos em casa que vimos q o porta mala não abria mais por fora pq foi batido e amassado. Prejuízo de R\$ 500,00 para arrumar!!!Sei que o estacionamento é terceirizado, mas esta no hotel [....] E foram desonestos...Muito obrigada!!! (Hóspede)

Nota-se que o cliente apesar de saber que o estacionamento era terceirizado, afirma que o mesmo estava dentro do hotel e que o ocorrido poderia ter sido controlado pelo hotel, incluindo assim, a culpa sobre o mesmo. Isso gerou um comentário negativo, possibilitando uma baixa chance de recompra do serviço.

A teoria explicada pela ótica de Weiner (2000) informa que ao ser identificado um problema por parte do consumidor, a empresa deve assumir a responsabilidade, mesmo que não a tenha, pois, o fato de assumir um ato reflete de maneira direta na confiabilidade para com o cliente. Assim, quanto a responsabilidade dos problemas, os hóspedes consideraram que o hotel é o responsável por quase todos os acontecimentos mencionados. Olhando pelo lado da gerência do hotel, obteve-se que, em $75 \%$ dos casos, eles assumiram a culpa dos fatos que ocorreram com os hóspedes. Isso diz que frente a um problema, possivelmente, para tentar amenizar a insatisfação percebida no cliente, os gerentes apresentavam como resposta algo que demonstrasse preocupação ou que tentasse fazer com que houvesse a possibilidade de o cliente retornar. Para melhor entender segue o exemplo: 
perderam minha encomenda na recepção Bom dia, estou há dias aguardando uma resposta do hotel quanto à minha encomenda deixada [....] no dia 21/02/17 na recepção do hotel. Ela deixou dois pijamas para que eu buscasse na recepção, mas eu voltei para minha cidade e esqueci. Hoje quando ligo para o hotel, depois de inúmeras tentativas e sem retorno, a atendente me diz que não estão encontrando minha encomenda. Não estou acreditando que um hotel [....] é capaz de perder um objeto deixado por um hóspede. Ainda estou aguardando uma resposta do hotel, ou procurarei os meios para ressarcimento, pois o objetivo ficou sob a responsabilidade do hotel. Já enviei vários e-mails, além de inúmeras ligações e estão me fazendo de besta, dizendo que vão me retornar e até agora nada. [....] (Hóspede)

sra [.... bom dia. Primeiro peço desculpas pela demora da minha equipe. Esse assunto já deveria ter sido resolvido de imediato. Recebi seu email ontem e estou levantando todas as informações. Ainda hoje ligo para a Sra e garanto que vamos resolver. Cordialmente, [....] (Gerência)

Diante do exemplo acima, entende-se que a responsabilidade foi posta sobre o hotel pela hóspede, a gerência entendendo que precisava resolver de pronto para que a imagem da marca não fosse prejudicada buscou entrar em contato com o hóspede, prometendo resolver o ocorrido o mais rápido possível. Isso demonstra uma tática de recuperação que reflete o assumir a culpa de algo, transmitindo positividade para a relação com o cliente.

Quando problemas acontecem após a compra de um produto ou serviço, as emoções dos indivíduos são reativadas. Tendo por base as emoções observadas nas análises, ou por meio dos sentimentos declarados pelos hóspedes nos comentários, o que mais se destacou foi a decepção seguida de satisfação (presente em indivíduos que embora tenham relatado problemas relevantes, tinham um grande apreço pela rede ou pelo hotel especificamente). Além disso, a insatisfação, como expressão emocional, também é muito citada na análise.

Os sentimentos são fatores que quando analisados transmitem informações importantes quanto ao comportamento do consumidor, pois demonstram seu real estado de consciência, possibilitando identificar o grau de satisfação e insatisfação. Um meio que pelo qual se utilizou para analisar tais sentimentos, além da percepção contextual e de frases, foi representado categoria 'destaques'. Isso mostrou que as pessoas faziam uso de duas formas para enfatizar o comentário ou sua opinião quanto aos problemas apresentados: o uso de caixa alta nas palavras ou frases, e emojis (que caracterizavam raiva). A seguir é dado um exemplo, demonstrando um caso que aborda o que foi dito acima:

grande decepção - Atendimento péssimo Apesar do hotel oferecer quartos amplos e confortáveis, o atendimento é péssimo. Equipe mal humorada, nunca tinham um sorriso no rosto. Fomos para um casamento e apesar de boa parte da família estar hospedada no hotel, além da noiva ter alugado um bangalô para se arrumar, a equipe da recepção foi grosseira nos atendimentos, nada gentil e cordial. Ao solicitarmos taças de espumante no quarto da noiva para um brinde, fomos informado da cobrança de $\mathrm{R} \$ 9,00$ a cada 2 taças. Cobram por emprestar taças vazias, sem bebida dentro e cobram pelo gelo também!! O isolamento acústico do quarto é péssimo, escutávamos as conversas do quarto ao lado e da TV, como se estivessem dentro do nosso quarto. Banheiro minúsculo e sem ventilação. Sinal de wi-fi péssimo. Grande decepção!! Não recomendo. (Hóspede)

excelente localização! Café da manhã muito bom com destaque para o Craque das Tapiocas: John ! Como Tapiocas todos os dias mas a do John garanto que foi a melhor da minha vida até hoje! O camarão Termidor do restaurante O Capo também é excelente! Único senão: a piscina tem sombra depois das 13:00 horas \# (Hóspede)

A categoria 'solicitação' não teve muita influência para os resultados, em vista que das duas categorias estipuladas para ela, apenas uma teve maior destaque que foi a de melhorias correspondendo às propostas apresentadas pelos hóspedes para solucionar os problemas ou fazer adições nos serviços prestados e na estrutura. Isso mostra que as pessoas não apresentaram muitas sugestões ou não reivindicaram sobre algum retorno ou reembolso especificamente.

Observa-se a seguir uma análise de uma interação entre um comentário de um hóspede de um determinado hotel e a resposta apresentada pela gerência desse hotel:

esperava mais $\mathrm{O}$ hotel não ofereceu serviços de café da manhã, almoço e jantar, não informando isso na hora da reserva. Entendo que não é necessários escrever mais para um serviço que deixou de ser prestado." (Hóspede). 
prezado cliente, Em nome de nossa equipe, muito obrigado por ter se hospedado conosco e por seus comentários sobre nosso produto e serviço. [....] Sobre os serviços de alimentação, sentimos muito que não saiste plenamente satisfeito, uma vez que, tomamos esta iniciativa para oferecer mais opções e serviços a nossos clientes e após colher feedback de muitos clientes com $100 \%$ de aprovação. Sinceramente acreditamos em nova oportunidade de conversarmos pessoalmente em breve para melhor entender suas necessidades [....] (Gerência)

No exemplo acima, pode-se perceber que o hotel afirma que o problema apresentado pelo hóspede (serviços de alimentação) permanecerá, mesmo que apresentando uma justificativa para a situação (a postura tomada estava de acordo com o consentimento de todos os outros clientes), o que enfatiza o conhecimento e responsabilidade sobre a situação. Isso mostra que, provavelmente, as chances de retorno do cliente serão baixas, além de proporcionar um boca a boca negativo, dificultando a divulgação de uma boa imagem da empresa.

A categoria 'mecanismo de recuperação', dividida em oito subcategorias, das quais três se destacam com maior frequência, que são: analisando os comentários (quando o hotel diz que as informações repassadas serão analisadas a fim de apurar o ocorrido), apresenta solução (quando o hotel afirma que o problema mencionado será resolvido apresentando uma proposta) e apresenta justificativa (quando o hotel apresenta uma explicação para o ocorrido).

Também com o objetivo de melhor analisar os pilares da teoria da Atribuição, criou-se a categoria 'formato de resposta', no qual 79\% das respostas passadas pelos responsáveis dos hotéis foram interativas para com os hóspedes. A subcategoria Interativa informa que a resposta apresentada pela gerência tratou de forma personalizada e reativa sobre o comentário feito pelo hóspede, demonstrando preocupação para com o hóspede. Em contraste existe a subcategoria programada, que retrata o oposto da interativa, sendo composta por respostas que possuem igual texto para situações diferentes. Abaixo, seguem dois exemplos para melhor visualização:

prezado [.... Foi um grande prazer receber seus comentários, é muito gratificante saber que se sentiu bem-vindo em nosso hotel e que nossa equipe tenha sido prestativa ... Sinto em saber sua impressão de nosso café da manhã e agradeço por compartilhar sua opinião, [....] Sinto que o café e as opções de frios não estavam a seu gosto. Permita-me informar que a proposta de nosso restaurante é trazer à mesa de nossos hóspedes opções mais saudáveis, por isso oferecemos opções de iogurtes produzidos no hotel, mas para atender aqueles que preferem os iogurtes industrializados, estes também estão disponíveis em nosso buffet. [....] Será um imenso prazer recebê-lo novamente. Abraços [....] Assistente do Gerente geral (Resposta Interativa da Gerência)

prezado(a), Sr (Sra), Obrigada pela escolha do hotel [....] como o seu meio de hospedagem na cidade de São Paulo! Lamentamos que não tenha sido possível corresponder completamente as suas expectativas. Tenha certeza que os apontamentos feitos em sua avaliação não demonstram os nossos padrões de qualidade e, por este motivo, os responsáveis pelos departamentos estão fazendo uma análise criteriosa para apurar qualquer eventualidade em sua hospedagem. Agradecemos também pela participação em nosso sistema interno de qualidade e por nos proporcionar a oportunidade de continuar trabalhando em função da satisfação dos nossos hóspedes! Cordialmente, [....] Gerente Geral (Resposta Programada da Gerência)

Com relação a categoria 'pedido de desculpas', a maior parte dos responsáveis não pediram desculpas pelo que foi relatado pelos hóspedes. Isso, provavelmente pode gerar maior desconforto para o cliente em retornar ao hotel. Já dizia Weiner (2000) que independente de ter responsabilidade ou não o melhor a ser feito é reconhecer o problema, facilitando a recompra e a confiabilidade.

\section{CONSIDERAÇÕES FINAIS}

O desenvolvimento do presente estudo possibilitou a análise de comunicações espontâneas dos hóspedes e das respostas dos hotéis, diante de problemas ocorridos durante hospedagens, tendo por base a teoria da atribuição. Os resultados encontrados foram que a maioria dos hóspedes informou que as causas dos problemas eram estáveis e que atribuíam o controle e responsabilidade à empresa. Diferente do que estes 
expressaram, a maioria das empresas hoteleiras buscou esclarecer que, em grande parte das situações, as causas eram instáveis. Sendo observado que estas assumiam o controle e a responsabilidade das ocorrências, possivelmente, com a pretensão de reatar o relacionamento com o hóspede e buscando fazer com que este contratasse o serviço novamente.

Com o intuito de verificar qual a postura dos hotéis no TripAdvisor.com, pôde-se perceber que as empresas hoteleiras têm a atitude de assumir o controle e responsabilidade das ocorrências apresentados, buscando resolver os problemas expostos, informando assim, que a causa é instável. Apesar disso, um grande problema identificado nos comentários é que algumas empresas não se preocupam em responder os comentários de forma individual e única para cada viajante e acabam respondendo com mensagens programadas, podendo deixar o hóspede com menor vontade de voltar aquele hotel.

Dessa forma, devido à grande influência das mídias sociais na vida das pessoas nos dias de hoje, principalmente porque as informações sobre compra de bens e serviços de empresas são postadas nesses meios e influenciam outros consumidores, as empresas precisam se envolver mais nessas plataformas. Isso faz com que elas busquem responder os consumidores da forma mais cordial e completa possível, lhes apresentando mais informações sobre os problemas vivenciados, para que outros futuros clientes não desistam da hospedagem devido ao que viram nas redes.

As organizações podem utilizar desses dados a fim de melhorar seu desempenho quanto ao relacionamento com os clientes, adotando novos métodos de abordagem e tratamento das informações disponíveis em plataformas virtuais a exemplo do TripAdvisor.com. Para um estudo futuro, fica a sugestão de abordar as emoções expressas pelos hóspedes como questão principal da pesquisa, buscando fazer uma análise mais profunda.

Apesar de o estudo conseguir analisar como se portam os hotéis frente às reclamações nas plataformas virtuais, ele tem como limitação não conseguir analisar os silêncios dos hóspedes que optam por não relatar nos sites sua opinião e experiência.

\section{REFERÊNCIAS}

BARDIN, L.. Análise de conteúdo. São Paulo: Edições 70, 2011.

CLÁUDIO, A. R. de S.; PEDRON, C. D.; GONÇALVES, P. A. O novo desafio da gestão de reclamações: as redes sociais. In: ENANPAD, 2014, Rio de Janeiro. ENANPAD 2014, 2014.

DELLAROCAS, C. The digitization of word of mouth: Promise and challenges of online feedback mechanisms. Management science, v. 49, n. 10, p. 1407-1424, 2003.

SOUSA, L. M. M; AZEVEDO, L. E. O uso de mídias sociais nas empresas: adequação para cultura, identidade e públicos. 2010.

DUBÉ, L.; MENON, K. Multiple roles of consumption emotions in post-purchase satisfaction with extended service transactions. International Journal of Service Industry Management, v. 11, n. 3, p. 287-304, 2000.

FOLKES, V. S.; KOLETSKY, S.; GRAHAM, J. L. A field study of causal inferences and consumer reaction: the view from the airport. Journal of consumer research, v. 13, n. 4, p. 534-539, 1987.

KOCAK, V. Y. How is social media communication competence and importance perceived and to what extent social media communication competence is implemented by business hotel managers within tourism industry in Norway and Turkey?. 2015. Dissertação de Mestrado. University of Stavanger, Norway. Disponível em: < https://brage.bibsys.no/xmlui/bitstream/handle/11250/301341/Kocak_Vedat.pdf?sequence=4>. Acesso em: 27 junho 2017.

KOTLER, P. Administração de marketing. 10 e. São Paulo: Pearson Prentice Hall, 2000.

KOTLER, P.; ARMSTRONG, G. Princípios de Marketing. 12 e. São Paulo: Pearson Prentice Hall, 2007.

LEUNG, D. et al. Social media in tourism and hospitality: A literature review. Journal of Travel \& Tourism Marketing, v. 30, n. 1-2, p. 3-22, 2013. 
LIMBERGER, P. F; BOARIA, F; DOS ANJOS, S. J. G. A relação entre a satisfação geral e as variáveis da satisfação na hotelaria em hotéis de excelência. Revista Brasileira de Pesquisa em Turismo, v. 8, n. 3, p. 435-455, 2014.

LOPES, F. F. P. A finalização de relacionamentos comerciais e o processo de atribuição no contexto de serviço. 2009. 105f. Dissertação (Mestrado em Administração) - Programa de Pós-Graduação em Administração, Universidade Estadual do Ceará, Fortaleza, 2009. Disponível em: . Acesso em: 15 julho 2017.

LOPES, F. F. P.; DE FREITAS, A. A. F.; DE OLIVEIRA MOTA, M. As Reações dos Consumidores diante das Falhas de Serviços a partir da Teoria da Atribuição. Revista de Ciências da Administração, v. 1, n. 1, p. 37-50, 2015.

MACLENNAN, M. L. F. et al. Associação entre intensidade de uso de mídias sociais, credibilidade e decisão de compra. Navus: Revista de Gestão e Tecnologia, v. 4, n. 2, p. 65-77, 2014.

MEDEIROS, S. A.; GOSLING, M.; VERA, L. A. R. Emoções em Experiências Negativas de Turismo: um estudo sobre a influência na insatisfação. Revista Turismo em Análise, v. 26, n. 1, p. 188-215, 2015.

PRADO, P. H. M.; FARIAS, S. A. Avaliação da atribuição e da desconfirmação como antecedentes da resposta de satisfação dos consumidores com serviços bancários. Anais de Marketing do, v. 22, p. 122, 1998.

SANTOS, C. P.; ROSSI, C. A. V. O impacto do gerenciamento de reclamações na confiança e na lealdade do consumidor. Revista de Administração Contemporânea, v. 6, n. 2, p. 49-73, 2002.

TOMLINSON, E. C.; MAYER, R. C. The role of causal attribution dimensions in trust repair. Academy of Management Review, v. 34, n. 1, p. 85-104, 2009.

WEINER, B. Attributional thoughts about consumer behavior. Journal of Consumer research, v. 27, n. 3, p. 382-387, 2000.

CC BY 